\title{
DERIVATIVE SPECTROPHOTOMETRIC METHOD FOR DETERMINATION OF ACYCLOVIR IN POLYMERIC NANOPARTICLES
}

\author{
Guilherme Diniz Tavares*, Gisele Miki Ishikawa, Talita Ferreira Monteiro, Carolina Zanolini, Érika Rosa Maria Kedor- \\ Hackmann, Nádia Araci Bou-Chacra e Vladi Olga Consiglieri
}

Faculdade de Ciências Farmacêuticas, Universidade de São Paulo, Av. Prof. Lineu Prestes, 580, 05508-900 São Paulo - SP, Brasil

Recebido em 28/2/11; aceito em 13/6/11; publicado na web em 8/8/11

\begin{abstract}
A derivative spectrophotometric method was validated for quantification of acyclovir in poly ( $n$-butylcyanoacrylate) (PBCA) nanoparticles. Specificity, linearity, precision, accuracy, recovery, detection (LOD) and quantification (LOQ) limits were established for method validation. First-derivative at $295.2 \mathrm{~nm}$ eliminated interferences from nanoparticle ingredients and presented linearity for acyclovir concentrations ranging from 1.25 to $40.0 \mu \mathrm{g} / \mathrm{mL}(\mathrm{r}=0.9999)$. Precision and accuracy data demonstrated good reproducibility. Recovery ranged from 99.3 to 101.2 . LOD was $0.08 \mu \mathrm{g} / \mathrm{mL}$ and $\mathrm{LOQ}, 0.25 \mu \mathrm{g} / \mathrm{mL}$. Thus, the proposed method proved to be easy, low cost, and accurate, and therefore, an useful alternative to quantify acyclovir in nanoparticles.
\end{abstract}

Keywords: acyclovir; polymeric nanoparticles; derivative spectrophotometry.

\section{INTRODUCTION}

In recent decades, there has been a considerable interest in the research of drug delivery using particulate systems as carriers for small and large molecules. Accordingly, nanoparticles have been used as a physical approach to modify and improve the pharmacokinetic and pharmacodynamic properties of a large number of drugs. ${ }^{1}$ Nanocarriers are currently being investigated for many therapeutic applications to overcome typical drug delivery challenges, such as increasing physicochemical stability, enhancing cellular uptake of poorly permeable molecules, reducing cellular and tissue clearance of drugs, as well as sustaining drug delivery. ${ }^{2,3}$ So, the therapeutic efficacy and safety of drugs can be significantly improved by targeted delivery using nanoparticles. ${ }^{4}$

Nowadays, much attention has been paid to the poly(alkylcyano-acrylate) (PACA) nanoparticles due to their ease of preparation, low toxicity and biodegradability. Thus, these systems are already employed in clinical development for cancer therapy. ${ }^{5}$ After oral administration, PACA nanoparticles can protect the active molecules and control their release by an erosion mechanism. ${ }^{6}$ On the other hand, the surface modification of these nanocarriers using polymers with specific properties has been reported to be a promising way to improve the oral bioavailability of drugs. ${ }^{7}$ Thereby, studies have established that a partially quaternized derivative of chitosan, $\mathrm{N}, \mathrm{N}, \mathrm{N}$ -trimethylchitosan (TMC), can be used as an absorption enhancer for large and/or hydrophilic compounds across intestinal epithelium..$^{8-10}$ TMC acts mainly by opening the tight junctions between epithelial cells to allow the paracellular transport of these compounds. ${ }^{11}$

As a consequence, recent nanoparticle systems exhibit new analytical challenges because of the wide variety of compounds in their composition and also, the need to detect smaller amounts of drugs. A significant number of techniques, specially spectrophotometry ${ }^{12-14}$ and high-performance liquid chromatography (HPLC), ${ }^{15-17}$ are described for the quantification of drugs in PACA nanoparticles. Conventional spectrophotometric methods are very susceptible to the presence of interferences in complex mixtures such as nanoparticules, requiring prior treatment or extraction of the analyte, and not always

*e-mail: diniztavares@usp.br providing adequate response. Despite the undoubted advantages of using HPLC technique, this one has some limitations such as the high cost of instrumentation and operation, relatively long time for analysis and the need of experience in handling the equipment and processing samples. In addition, the disadvantages related to the use of solvents such as discharge, operator health and environmental damage encourage the development of simpler and faster methods, with smaller amounts of solvents and without prior extraction steps. In this sense, derivative spectrophotometric method with detection in UV is low cost and is easily applied to analysis of raw materials and pharmaceuticals, as well as in kinetic studies of drug release, detection of analyte in the presence of decomposition compounds, and many other applications. ${ }^{18}$

Derivative spectrophotometry (DS) is based on so called derivative spectra which are generated from conventional or zero-order scan. The derivatization of zero-order spectrum can lead to the separation of overlapped signals and elimination of background caused by presence of other compounds in a sample without previous separation or purification. Nowadays, this technique is considered a very useful additional tool which helps to solve various analytical problems. Several applications have been found in many areas of analysis, especially in pharmaceutical. ${ }^{19-21}$

Some methods employing DS were reported to the quantification of acyclovir (9-[2-hydroxyethoxymethyl]-9H-guanine, ACV) (Figure 1) in order to quantify this drug in pharmaceutical dosage forms, such as injections and creams ${ }^{22}$ or in the presence of guanine, its main impurity. ${ }^{23}$ Nevertheless, according to our knowledge, there are no reports concerning the quantification of ACV in PACA nanoparticles by this technique.

In this sense, the aim of this work was to purpose a rapid and effective first-order spectrophotometric method to quantify ACV in<smiles>Nc1nc2c(ncn2COCCO)c(=O)[nH]1</smiles>

Figure 1. Chemical structure of $A C V$ 
empirical formulation containing poly( $n$-butylcyanoacrylate) (PBCA) nanoparticles coated or uncoated with TMC.

\section{EXPERIMENTAL}

\section{Apparatus and conditions}

A Shimadzu ${ }^{\circledR}$ UV-1601 double-beam spectrophotometer with $1.0 \mathrm{~cm}$ quartz cells and data processing capacity was used. The first-order derivative (zero-crossing method) spectra were obtained over the 220.0-320.0 $\mathrm{nm}$ range, $\Delta \lambda=2.0 \mathrm{~nm}$, scaling factor $=1.0$ and amplitude $= \pm 0.1$. The determinations were made at $295.2 \mathrm{~nm}\left({ }^{1} \mathrm{D}_{295.2}\right)$. Methanol:Acetonitrile $(\mathrm{MeOH}: \mathrm{ACN})(8: 2 \mathrm{v} / \mathrm{v})$ was used as solvent mixture.

\section{Chemicals}

Acyclovir reference standard ( $~ 99 \%$ purity) was kindly supplied by Aché Pharmaceuticals Laboratories (São Paulo, SP, Brazil). Acyclovir raw material of pharmaceutical grade was kindly donated by Medley Pharmaceutical Industry (Campinas, SP, Brazil). The monomer $n$-butylcyanoacrylate was purchased from B. Braun Laboratories (Tuttlingen, Baden-Württemberg, Germany). Chitosan (low molecular weight, 92\% deacetylated, viscosity $20000 \mathrm{cps}$ ) and Dextran 70.000 were obtained from Sigma Chemical Company (St Louis, MO, USA). Methyl iodide was purchased from Merck (Darmstadt, Hessen, Germany). All other chemicals and solvents used were of analytical grade. $\mathrm{N}, \mathrm{N}, \mathrm{N}$-trimethylchitosan was synthesized by reductive methylation of chitosan based on a previously described method ${ }^{24}$ and ${ }^{1} \mathrm{H}$-nuclear magnetic resonance spectra was obtained (Figure 1S, supplementary material).

\section{Nanoparticles preparation}

\section{Synthesis of PBCA nanoparticles}

Poly(n-butylcyanoacrylate) nanoparticles (PBCA) were obtained by emulsion polymerization according to the method described by Couvreur and Vauthier ${ }^{25}$ with some modifications: n-butylcyanoacrylate monomer $(1.0 \%)$ was added dropwise under magnetic stirring

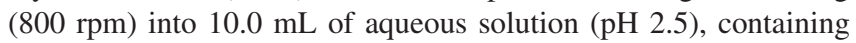
Dextran $70(1.0 \%)$. After 4 h, about $100.0 \mu \mathrm{L}$ of $0.1 \mathrm{M} \mathrm{NaOH}$ was added, until neutralization of colloidal suspension.

\section{Preparation of PBCA-TMC nanoparticles}

Coated nanoparticles were prepared by incubation of TMC aqueous solution $(2.5 \mathrm{~mL}, 0.5 \% \mathrm{w} / \mathrm{v})$ in $5.0 \mathrm{~mL}$ of nanoparticles suspension under magnetic stirring $(50 \mathrm{rpm})$ for $1 \mathrm{~h}$.

\section{Method validation}

\section{Reference standard stock solutions}

Standard ACV was accurately weighed $(100.0 \mathrm{mg})$ and transferred to a $250.0 \mathrm{~mL}$ volumetric flask. $\mathrm{HCl}$ solution $(0.1 \mathrm{M}, 1.0 \mathrm{~mL})$ was added to promote total dissolution and the volume was completed with MeOH:ACN (8:2 v/v). This solution was diluted with the same solvent, obtaining the ACV concentration of $20.0 \mu \mathrm{g} / \mathrm{mL}$.

\section{Placebo solutions}

PBCA nanoparticles (placebo 1) and PBCA-TMC nanoparticles (placebo 2)

An aliquot of $10.0 \mathrm{~mL}$ of the PBCA nanoparticles suspension (or PBCA-TMC nanoparticles suspension) was transferred to a 250.0 $\mathrm{mL}$ volumetric flask followed by addition of $\mathrm{HCl}$ solution $(0.1 \mathrm{M}$, $1.0 \mathrm{~mL})$, and the volume was completed with $\mathrm{MeOH}: \mathrm{ACN}(8: 2 \mathrm{v} / \mathrm{v})$.
Then, $5.0 \mathrm{~mL}$ were transferred to a $100.0 \mathrm{~mL}$ volumetric flask and the volume was completed with the same solvent. Finally, $15.0 \mathrm{~mL}$ were centrifugated (10.000 rpm, $60 \mathrm{~min}$, at room temperature) and the supernatant was used for measurements.

Sample solutions

PBCA nanoparticles with ACV (sample 1) and PBCA-TMC nanoparticles with ACV (sample 2)

Aliquots of $100.0 \mathrm{mg}$ of ACV and $10.0 \mathrm{~mL}$ of PBCA nanoparticles suspension (or PBCA-TMC nanoparticles with ACV) were transferred to a $250.0 \mathrm{~mL}$ volumetric flask followed by the addition of $\mathrm{HCl}$ solution $(0.1 \mathrm{M}, 1.0 \mathrm{~mL})$ to promote total dissolution of $\mathrm{ACV}$ and the volume was completed with $\mathrm{MeOH}: \mathrm{ACN}$ (8:2 v/v). Then, 5.0 $\mathrm{mL}$ of this solution were transferred to a $100.0 \mathrm{~mL}$ volumetric flask and the volume was completed with the same solvent. The final ACV concentration was $20.0 \mu \mathrm{g} / \mathrm{mL}$. Finally, $15.0 \mathrm{~mL}$ of this last solution was centrifugated (10.000 rpm, $60 \mathrm{~min}$, at room temperature) and the supernatant was used for measurements.

\section{Blank solution}

Blank solution was prepared by transferring $1.0 \mathrm{~mL}$ of $01 . \mathrm{M} \mathrm{HCl}$ solution to a $250.0 \mathrm{~mL}$ volumetric flask and completing volume with $\mathrm{MeOH}: \mathrm{ACN}(8: 2 \mathrm{v} / \mathrm{v})$.

\section{Specificity}

The specificity of the method was evaluated by the analysis of standard solution, placebo solutions (1 and 2) as well as sample solutions (1 and 2). Zero-order spectra were obtained over the 220-320 $\mathrm{nm}$ range. From this, first-order derivative spectra were obtained.

\section{Linearity}

Aliquots from the stock solutions of ACV were transferred to volumetric flasks and diluted with blank solution to obtain the final concentrations of 1.25, 2.5, 5.0, 8.0, 10.0, 16.0, 20.0 and $40.0 \mu \mathrm{g} / \mathrm{mL}$. Each solution was prepared in triplicate. The first-order derivative spectra (zero-crossing method) were obtained over the 220.0-320.0 $\mathrm{nm}$ range and determinations were made at $295.2 \mathrm{~nm}$. The linearity was evaluated by linear regression analysis, which was calculated by the least square regression method.

\section{Precision and accuracy}

Aliquots of $10.0 \mathrm{~mL}$ from placebos 1 and 2 were added to known amounts of standard solutions of ACV (25.0, 100.0 and 200.0 $\mu \mathrm{g} / \mathrm{mL})$. Each sample was diluted with blank solution to analytical concentrations $(2.5,10.0$ and $20.0 \mu \mathrm{g} / \mathrm{mL})$, centrifugated $(10.000$ $\mathrm{rpm}, 60 \mathrm{~min}$, at room temperature) and supernatants were used for measurements. Precision and accuracy were calculated intra- and inter-day as RSD and $E$, respectively, as established by ICH in the Validation of Analytical Procedure-Methodology. ${ }^{26}$

\section{Detection (LOD) and Quantification (LOQ) limits}

Detection and quantification limits were estimated by the slope and mean standard deviation of standard ACV concentrations employed to construct the calibration curve. ${ }^{26}$

\section{Recovery}

Aliquots of samples 1 and $2(20.0 \mu \mathrm{g} / \mathrm{mL}$ of ACV) were added to known amounts of standard solutions of ACV (80.0, 130.0 and 180.0 $\mu \mathrm{g} / \mathrm{mL})$. Each sample was diluted with blank solution to analytical concentrations $(10.0,15.0$ and $20.0 \mu \mathrm{g} / \mathrm{mL})$. Solutions were recorded in the range of $220.0-320.0 \mathrm{~nm}$ and determinations were made at $295.2 \mathrm{~nm}$. Recovery was performed in nine replicates. ${ }^{26}$ 


\section{RESULTS AND DISCUSSION}

The literature describes the use of different solvents in order to disrupt the PBCA nanoparticles for subsequent quantification of the associated drug, such as chloroform, ${ }^{12}$ ethanol,,${ }^{13}$ methanol ${ }^{16}$ and acetonitrile. ${ }^{27}$ These solvents, as well as their mixtures in different proportions, were evaluated through visual observation with regard to their ability of efficiently disrupt nanoparticles. The best solvent composition was found to be $\mathrm{MeOH}: \mathrm{ACN}(8: 2, \mathrm{v} / \mathrm{v})$; however, a previous addition of $\mathrm{HCl}$ solution $(0.1 \mathrm{M}, 1.0 \mathrm{~mL})(\mathrm{pH} 1.2)$ was necessary to ensure complete solubilization of ACV.

The zero-order spectra from ACV in PBCA or PBCA-TMC nanoparticles showed complete overlapping as can be observed in Figure 2. Therefore classical UV method cannot be applied. So, to assure no significance of these signals from placebos, nominal derivative values were evaluated. The first-derivative $\left({ }^{1} \mathrm{D}\right)$ spectra from placebo 1 and 2, ACV, and nanoparticle systems (uncoated and coated with TMC) were presented by Figure 3. In this figure, it is possible to observe that all interferences were cancelled out at the wavelength of $295.2 \mathrm{~nm}$.

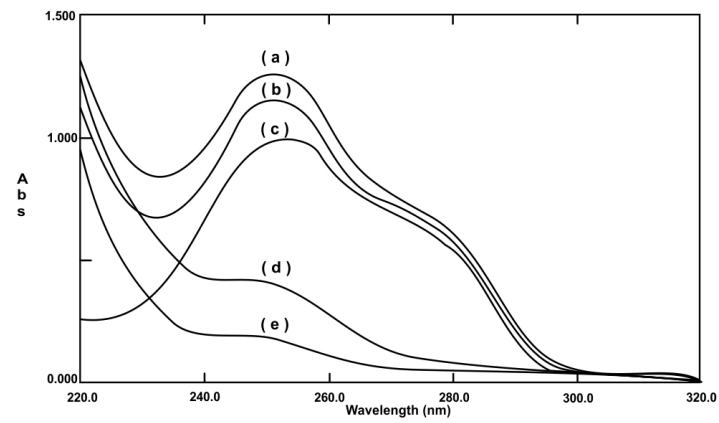

Figure 2. Zero-order absorbance spectra of (a) PBCA-TMC with ACV (20.0 $\mu \mathrm{g} / \mathrm{mL})$, (b) PBCA with ACV $(20.0 \mu \mathrm{g} / \mathrm{mL})$, (c) ACV $(20.0 \mu \mathrm{g} / \mathrm{mL})$, (d) PBCATMC, (e) PBCA. Abs = absorbance

In addition, in order to improve the ${ }^{1} \mathrm{D}$ method, different smoothing and scaling factors were tested, where a smoothing factor of $\Delta \lambda$ $=2.0$ and a scaling factor $=1.0$ showed a suitable signal-to-noise ratio and spectra showed good resolution. A linear correlation ( $r$ $=0.9999$ ) was obtained between peak amplitude at $295.2 \mathrm{~nm}$ and the corresponding concentration for $\mathrm{ACV}$ in the range of 1.25 and $40.0 \mu \mathrm{g} / \mathrm{mL}$ (Figure $2 \mathrm{~S}$, supplementary material). The linear regres-

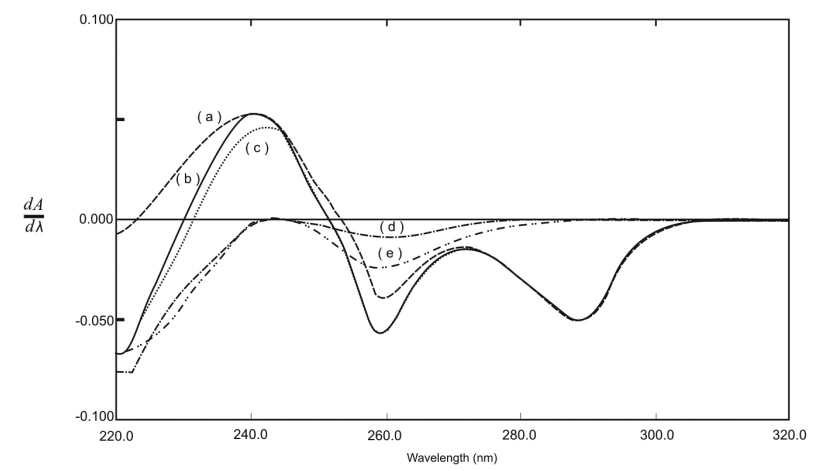

Figure 3. First-order derivative spectra of (a) $P B C A$ with $A C V(20.0 \mu \mathrm{g} / \mathrm{mL})$, (b) ACV $(20.0 \mu \mathrm{g} / \mathrm{mL})$, (c) PBCA-TMC with ACV $(20.0 \mu \mathrm{g} / \mathrm{mL})$, (d) PBCA, (e) PBCA-TMC

sion equation was found to be: $y=0.0024 x+0.0004$.

Intra- and inter-day precision, calculated as RSD, and accuracy values are reported in Tables 1 and 2. Relative small amount of RSD, not exceeding the limit of $5.0 \%$, with mean values for intra- and interrun assays were 0.79 and $1.87 \%$ for the PBCA nanoparticles (placebo 1). For the PBCA-TMC nanoparticles (placebo 2) these values were 0.65 and $2.89 \%$, respectively, and confirmed the precision, reproducibility and repeatability of the first derivative method at $295.2 \mathrm{~nm}$. Accuracy mean values (intra- and inter-day) were 101.6 and $101.0 \%$ for the PBCA nanoparticles (placebo 1), whereas for the PBCA-TMC nanoparticles (placebo 2) were 100.3 and $100.7 \%$.

LOD and LOQ were estimated as $0.08 \mu \mathrm{g} / \mathrm{mL}$ and $0.25 \mu \mathrm{g} / \mathrm{mL}$, respectively. Recovery experiment was conducted to corroborate the accuracy of the proposed zero-crossing first-derivative spectrophotometric method. The mean recovery value $(n=9)$ for PBCA and PBCA-TMC samples with standard ACV was 100.3 and 100.2, respectively (Tables 3 and 4), indicating acceptable accuracy.

\section{CONCLUSIONS}

Up to now, no derivative procedures have been described for assay of ACV present in PACA nanoparticles preparations. As a result, a new derivative spectrophotometric method was developed for determination of this drug in polymeric nanoparticles coated or uncoated with TMC. This described method has eliminated the interference from excipients, allowing the quantification of ACV in these formulations with good accuracy. The method showed to be simple, rapid, sensitive

Table 1. Intra- and inter-day assays for determination of precision and accuracy of DS method ( $295.2 \mathrm{~nm}$, zero-crossing) for placebo 1

\begin{tabular}{|c|c|c|c|c|c|c|}
\hline \multirow[b]{2}{*}{ Analytical concentrations $(\mu \mathrm{g} / \mathrm{mL})$} & \multicolumn{3}{|c|}{ Intra-day } & \multicolumn{3}{|c|}{ Inter-day } \\
\hline & Means $^{\mathrm{a}} \pm$ s.d. $(\mu \mathrm{g} / \mathrm{mL})$ & $\operatorname{RSD}(\%)$ & $\mathrm{E}(\%)$ & Means $^{\mathrm{b}} \pm$ s.d. $(\mu \mathrm{g} / \mathrm{mL})$ & $\operatorname{RSD}(\%)$ & $\mathrm{E}(\%)$ \\
\hline 2.5 & $2.53 \pm 0.045$ & 1.78 & 101.4 & $2.44 \pm 0.072$ & 2.95 & 97.6 \\
\hline 10.0 & $10.21 \pm 0.046$ & 0.45 & 102.1 & $10.26 \pm 0.170$ & 1.65 & 102.6 \\
\hline 20.0 & $20.28 \pm 0.027$ & 0.13 & 101.4 & $20.56 \pm 0.210$ & 1.02 & 102.8 \\
\hline
\end{tabular}

${ }^{\mathrm{a}} \mathrm{n}=3 ;{ }^{\mathrm{b}} \mathrm{n}=9$; s.d. $=$ standard deviation; precision $=$ relative standard deviation $(\mathrm{RSD}) ; \mathrm{E}=$ accuracy.

Table 2. Intra- and inter-day assays for determination of precision and accuracy of DS method (295.2 nm, zero-crossing) for placebo 2

\begin{tabular}{|c|c|c|c|c|c|c|}
\hline \multirow[b]{2}{*}{ Analytical concentrations $(\mu \mathrm{g} / \mathrm{mL})$} & \multicolumn{3}{|c|}{ Intra-day } & \multicolumn{3}{|c|}{ Inter-day } \\
\hline & Means $^{\mathrm{a}} \pm$ s.d. $(\mu \mathrm{g} / \mathrm{mL})$ & $\operatorname{RSD}(\%)$ & $\mathrm{E}(\%)$ & Means $^{\mathrm{b}} \pm$ s.d. $(\mu \mathrm{g} / \mathrm{mL})$ & $\operatorname{RSD}(\%)$ & $\mathrm{E}(\%)$ \\
\hline 2.5 & $2.49 \pm 0.024$ & 0.96 & 99.68 & $2.46 \pm 0.10$ & 4.06 & 98.4 \\
\hline 10.0 & $10.05 \pm 0.08$ & 0.79 & 100.50 & $10.31 \pm 0.26$ & 2.52 & 103.1 \\
\hline 20.0 & $20.19 \pm 0.039$ & 0.19 & 100.95 & $20.16 \pm 0.42$ & 2.08 & 100.8 \\
\hline
\end{tabular}

${ }^{\mathrm{a}} \mathrm{n}=3 ;{ }^{\mathrm{b}} \mathrm{n}=9 ;$ s.d. = standard deviation; precision = relative standard deviation $(\mathrm{RSD}) ; \mathrm{E}=$ accuracy. 
Table 3. Results obtained from recovery tests of ACV from PBCA nanoparticles by DS method ( $295.2 \mathrm{~nm}$, zero-crossing)

\begin{tabular}{lcccc}
\hline \multicolumn{5}{c}{ Concentration $(\mu \mathrm{g} / \mathrm{mL})$} \\
Standard & Sample & $\begin{array}{c}\text { Final } \\
\text { concentration }\end{array}$ & $\begin{array}{c}\text { Found } \\
\left(\text { mean }^{\mathrm{a}} \pm \mathrm{s.d} .\right)\end{array}$ & $\begin{array}{c}\text { Recovery } \\
(\%)\end{array}$ \\
\hline 80.0 & 20.0 & 10.0 & $10.01 \pm 0.014$ & 100.1 \\
130.0 & 20.0 & 15.0 & $14.97 \pm 0.024$ & 99.8 \\
180.0 & 20.0 & 20.0 & $20.24 \pm 0.041$ & 101.2 \\
\hline
\end{tabular}

${ }^{\mathrm{a}} \mathrm{n}=3$; s.d. = standard deviation.

Table 4. Results obtained from recovery tests of ACV from PBCA-TMC nanoparticles by DS method ( $295.2 \mathrm{~nm}$, zero-crossing)

Concentration $(\mu \mathrm{g} / \mathrm{mL})$

\begin{tabular}{lcccc} 
Standard & Sample & $\begin{array}{c}\text { Final } \\
\text { concentration }\end{array}$ & $\begin{array}{c}\text { Found } \\
\left(\text { mean }^{\mathrm{a}} \pm \text { s.d. }\right)\end{array}$ & $\begin{array}{c}\text { Recovery } \\
(\%)\end{array}$ \\
\hline 80.0 & 20.0 & 10.0 & $9.93 \pm 0.019$ & 99.3 \\
130.0 & 20.0 & 15.0 & $15.12 \pm 0.028$ & 100.8 \\
180.0 & 20.0 & 20.0 & $20.10 \pm 0.060$ & 100.5 \\
\hline
\end{tabular}

${ }^{\mathrm{a}} \mathrm{n}=3$; s.d. = standard deviation.

and precise and could be easily applied in the determination of ACV associated to these nanocarries. Hence, first-derivative presented to be an useful analytical method for precise and accurate determination of ACV in PBCA and PBCA-TMC nanoparticles.

\section{SUPPLEMENTARY MATERIAL}

Available at http://quimicanova.sbq.org.br, in pdf file, with free access.

\section{ACKNOWLEDGMENTS}

The authors would like to thank CNPq and CAPES for scholarships financial support, and also Aché Pharmaceuticals Laboratories and Medley Pharmaceutical Industry for gently supply acyclovir pharmaceutical grade.

\section{REFERENCES}

1. Mohanraj, V. J.; Chen, Y.; Trop. J. Pharm. Res. 2006, 5, 561.

2. Mallipeddi, R.; Rohan, L. C.; Int. J. Nanomedicine 2010, 5, 533.

3. Ishihara, T.; Mizushima, T.; Expert Opin. Drug Deliv. 2010, 7, 565.

4. Suri, S. S.; Fenniri, H.; Singh, B.; J. Occup. Med. Toxicol. 2007, 2, 16.

5. Vauthier, C.; Dubernet, C.; Fattal, E.; Pinto-alphandary, H.; Couvreur, P.; Adv. Drug Deliver. Rev. 2003, 55, 519.

6. Chauvierre, C.; Leclerc, L.; Labarre, D.; Appel, M.; Marden, M. C.; Couvreur, P.; Vauthier, C.; Int. J. Pharm. 2007, 338, 327.

7. Bravo-osuna, I.; Vauthier, C.; Chacun, H.; Ponchel, G.; Eur. J. Pharm. Biopharm. 2008, 69,436.

8. Jonker, C.; Hamman, J. H.; Kotzé, A. F.; Int. J. Pharm. 2002, 238, 205.

9. Mourya, V. K.; Inamdar, N. N.; J. Mater. Sci.: Mater. Med. 2009, 20, 1057.

10. Werle, M.; Takeuchi, H.; Bernkop-Schnürch, A.; J. Pharm. Sci. 2009, 98, 1643.

11. Polnok, A.; Borchard, G.; Verhoef, J. C.; Sarisuta, N.; Junginger, H. E.; Eur. J. Pharm. Biopharm. 2004, 57, 77.

12. Weiss, K.; Lorenz, M.; Landfester, K.; Mailander, V.; Macromol. Biosci. 2007, 7, 883 .

13. Mulik, R.; Mahadik, K.; Paradkar, A.; Eur. J. Pharm. Sci. 2009, 37, 395.

14. Liu, H.; Chen, J.; PDA J. Pharm. Sci. Tech. 2009, 63, 207.

15. Xi-xiao, Y.; Jan-hai, C.; Shi-ting, L.; Dan, G.; Xv-xin, Z.; Reg. Tox. Pharm. 2006, 46, 211.

16. He, M.; Zhao, Z.; Yin, L.; Tang, C.; Yin, C.; Int. J. Pharm. 2009, 373, 165.

17. Luo, D. Q.; Guo, J. H.; Wang, F. J.; Jin, Z. X.; Cheng, X. L.; Zhu, J. C.; Peng, C. Q.; Zhang, C.; J. Biomater. Sci., Polym. Ed. 2009, 20, 21.

18. Siqueira-Moura, M. P.; Lira, M. C. B.; Santos-Magalhães, N. S.; Rev. Bras. Cienc. Farm. 2008, 44, 621.

19. Karpinska, J.; Talanta 2004, 64, 801

20. Bosch Ojeda, C.; Sanches Rojas, F.; Anal. Chim. Acta 2004, 518, 1.

21. Mendez, A. S. L.; Deconto, L.; Garcia, C. V.; Quim. Nova 2010, 33, 981.

22. Mahrous, M. S.; Abdel-Khalek, M. M.; Daabees, H. G.; Beltagy, Y. A.; Anal. Lett. 1992, 25, 1491.

23. Daabees, H. G.; Anal. Lett. 1998, 31, 1509.

24. Curti, E.; Britto, D.; Campana-Filho, S. P.; Macromol. Biosci. 2003, 3, 571.

25. Couvreur, P.; Vauthier, C.; J. Controlled Release 1991, 17, 187.

26. ICH - International Conference on Harmonization of Technical Requeriments for Registration of Pharmaceuticals for Human Use, $Q 2 B(R 1)$ : Guideline on Validation of Analytical Procedure-Methodology, 2005.

27. Maksimenko, O.; Pavlov, E.; Toushov, E.; Molin, A.; Stukalov, Y.; Prudskova, T.; Feldman, V.; Kreuter, J.; Gelperina, S.; Int. J. Pharm. 2008, 356, 325 . 


\section{DERIVATIVE SPECTROPHOTOMETRIC METHOD FOR DETERMINATION OF ACYCLOVIR IN POLYMERIC}

\section{NANOPARTICLES}

Guilherme Diniz Tavares*, Gisele Miki Ishikawa, Talita Ferreira Monteiro, Carolina Zanolini, Érika Rosa Maria KedorHackmann, Nádia Araci Bou-Chacra e Vladi Olga Consiglieri

Faculdade de Ciências Farmacêuticas, Universidade de São Paulo, Av. Prof. Lineu Prestes, 580, 05508-900 São Paulo - SP, Brasil

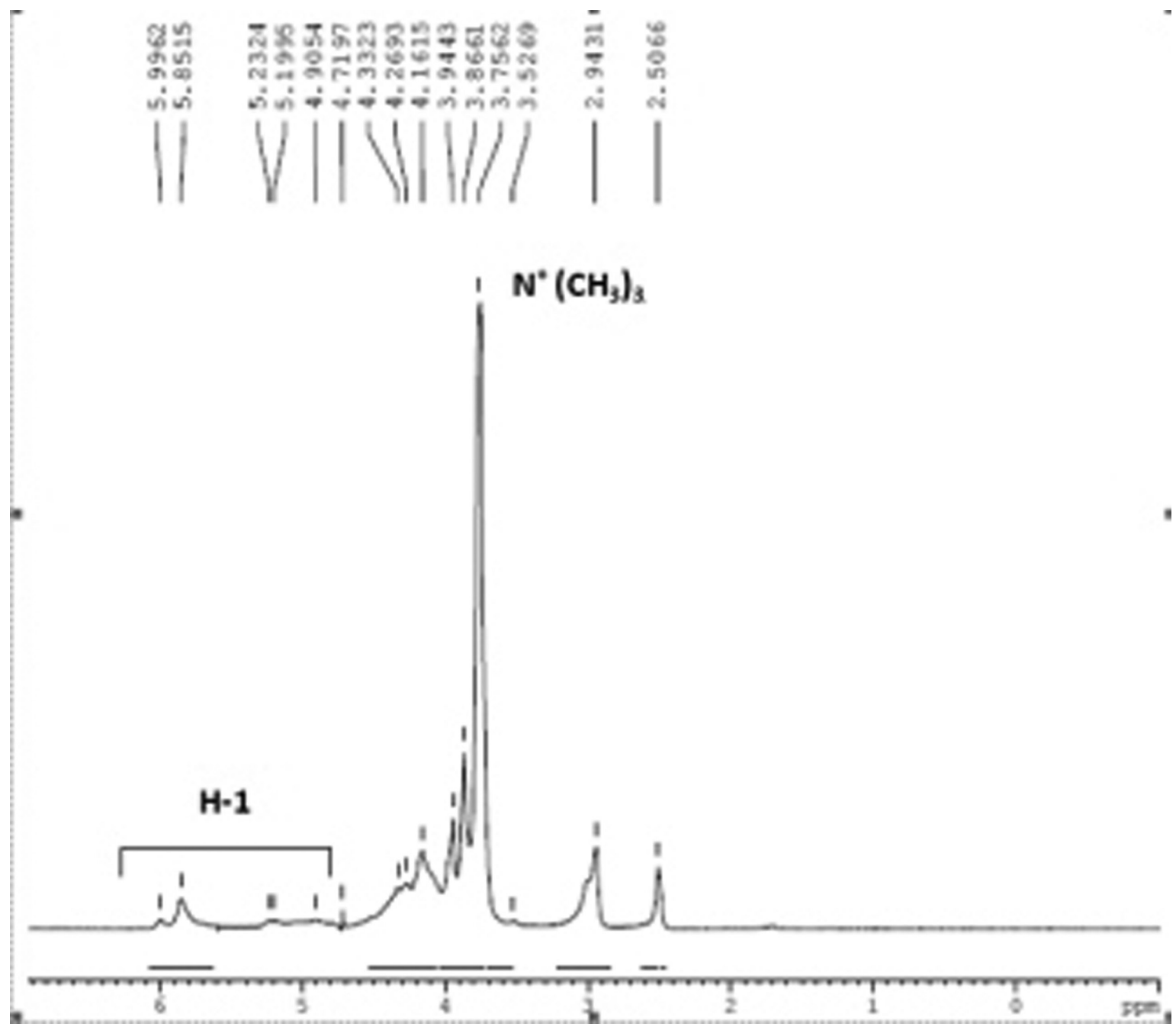

Figure 1S. ${ }^{1} \mathrm{H}$-NMR spectra of the TMC

*e-mail: diniztavares@usp.br 


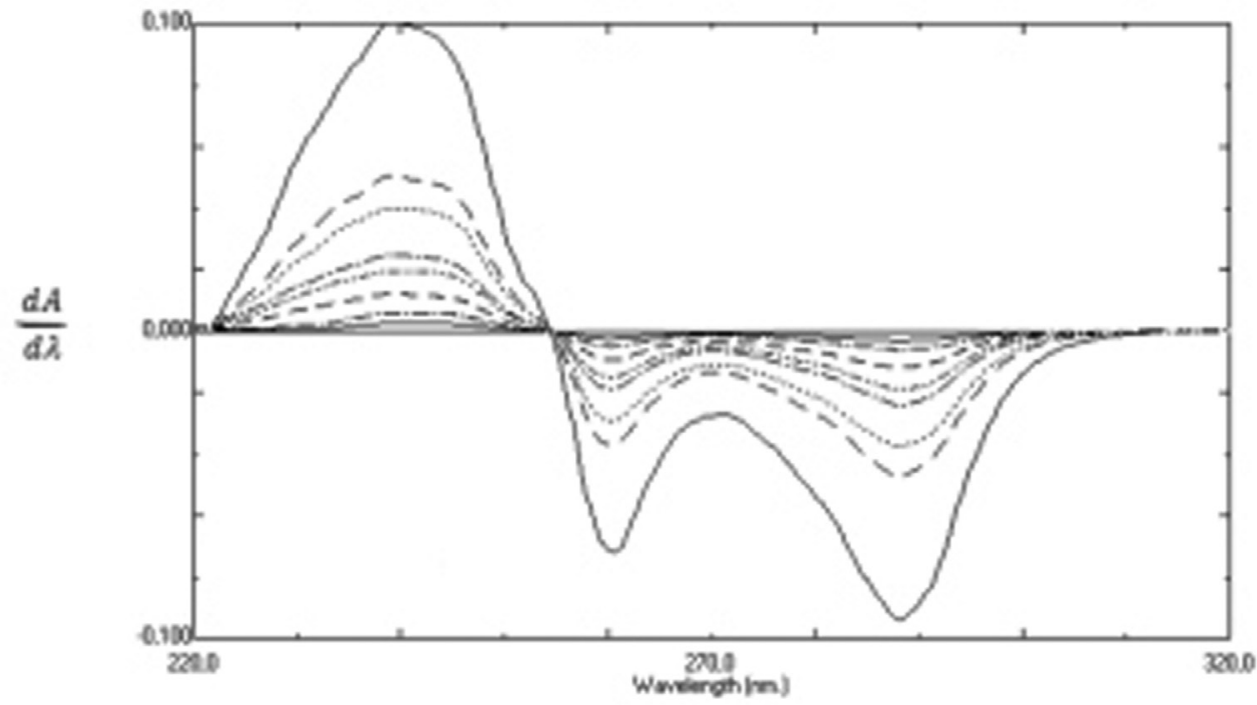

Figure 2S. First-order derivative overlapped spectra of ACV standard. Concentrations were 1.25, 2.5, 5.0, 8.0, 10.0, 16.0, 20.0 and $40.0 \mu \mathrm{g} / \mathrm{mL}$ 